\title{
IDENTIFYING SIMPLE SEQUENCE REPEAT (SSR) MARKER LINKED TO MITE TOLERANCE IN JUTE SPECIES
}

\author{
Shamima Islam Keka, Md. Shamsuzzaman ${ }^{1}$, Minhaz Uddin Pahloan, \\ Sultana Pervin, Md. Maksuder Rahman ${ }^{2}$ and Haseena Khan ${ }^{*}$ \\ Department of Biochemistry and Molecular Biology, University of Dhaka, \\ Dhaka-1000, Bangladesh
}

Key words: Jute, Mite tolerance, SSR marker, Linkage mapping

\begin{abstract}
Mite infestation is one of the main factors restricting jute production in Bangladesh. The utilization of jute cultivars tolerant to mite attack can be one of the most economic strategies for expanding jute production. Among jute genotypes, C. olitorius O-7/95 has been reported to be most tolerant to mite attack. SSR or microsatellite markers for jute have been successfully used in distinguishing mite sensitive and tolerant jute varieties. To increase selection efficiency for mite tolerance we have used an $\mathrm{F}_{2}$ population of O-7/95 and O-72 (sensitive to mite attack) to map a number of these microsatellite markers and to determine their linkage with mite tolerant trait. A preliminary genetic linkage map based on $35 \mathrm{~F}_{2}$ populations, was constructed using software MAPMAKER/EXP (ver 3.0b). This map was based on ten SSR markers and a phenotypic marker (M-11) related to mite sensitivity. In this analysis mite resistance has been found to be linked with a SSR marker, M-66 at LOD threshold of 3. This marker has the potential of being useful in Marker Assisted Selection (MAS) in jute breeding programs for selection of lines resistant to mite.
\end{abstract}

\section{Introduction}

With the advent of molecular marker based techniques, the scope for characterization of genetic variability in plants presents immense opportunities. Marker-dense genetic maps contribute greatly to our understanding of evolutionary process, enable marker assisted-selection and mapping of agronomic traits and facilitate many aspects of crop improvement.

Many linkage maps in plants are based on $\mathrm{F}_{2}$ population or recombinant inbred line (RIL) populations (Burr et al. 1988, Gardiner et al. 1993, Röder et al. 1998, Davis et al. 1999, Temnykh et al. 2000). The aim of linkage mapping is to find out the approximate location of genes relative to genetic markers on a chromosome based on recombination frequencies observed in pedigrees or progeny populations (Clark and Wall 1996). Polymorphism between individuals in a population and their detection with genetic markers are essential elements of linkage mapping. Construction of a genetic linkage map requires selection of an appropriate population, defining markers or genes, calculation of pair-wise recombination frequencies, establishment of linkage groups, determination of gene or marker order and estimation of map distances (Staub et al. 1996).

A number of PCR-based marker technologies have expedited the construction of high-density linkage maps; facilitated genetic analysis and map based cloning (Yang et al. 2002, Peters et al. 2003). These techniques involve RFLP (McCouch et al. 1997), RAPD (Williams et al. 1990), AFLP (Vos et al. 1995), SSR (Tautz 1989).

PCR-based markers like the Simple Sequence Repeat (SSR) or microsatellite markers are robust, inexpensive to assay, easily shared among researchers, and readily accessible in public and private domains, making them a much more appropriate approach for developing countries. With

"Corresponding author: E-mail: <haseena@bangla.net>. ${ }^{1}$ Department of Genetic Engineering and Biotechnology, University of Dhaka, Dhaka-1000, Bangladesh. ${ }^{2}$ Bangladesh Jute Research Institute, Dhaka1207, Bangladesh. 
access to a simple text file containing the sequences of the oligonucleotide primers for the PCRbased markers of interest, a breeder can rapidly and efficiently evaluate the germplasm under study.

Microsatellite based linkage maps have been constructed for a wide variety of species including man (Dib et al. 1996), mouse (Dietrich et al. 1996), a number of plant species, such as maize (Chin et al. 1996, Taramino and Tingey 1996), rice (Temnykh et al. 2000), wheat (Bryan et al. 1997, Röder et al. 1998), potato (Milbourne et al. 1998) and soybean (Akkaya et al. 1995, Cregan et al. 1999). There are many reports on the identification of SSR markers associated with pest resistance (Fu et al. 2006, Shalini et al. 2007).

In Bangladesh, jute (Corchorus spp. $2 n=14$; genome size $=1,250 \mathrm{Mb}$ ) suffers from losses both in quantity and quality due to attack of about 40 species of different kinds of insects and mite pests. Yellow mite (Polyphagotarsonemus latus) is the most destructive pest of both the cultivated species of jute (C. capsularis and C. olitorius) and its incidence is very high in the field during summer seasons especially from April to July when about $38 \%$ yield loss occur.

However, some varieties of jute show resistance toward mite. C. olitorius has two recommended varieties, cv. O-72, mite sensitive and cv. O-7/95 is mite tolerant. In this study, to establish linkages between molecular markers and mite resistance traits using an $\mathrm{F}_{2}$ population raised from a cross between mite sensitive O-72 and tolerant O-7/95 was tried. Molecular MarkerAssisted Selection (MAS) for mite resistance in jute would be very convenient in terms of increasing breeding efficiency, and genetic maps would be a useful tool to implement this strategy. Recently a number of microsatellite markers (SSR) have been developed for jute (Mir et al. 2008, Akter et al. 2008).

With some of the microsatellite markers at hand, the present work was undertaken to study them in a segregating $F_{2}$ population in order to (i) determine their linkage to mite resistance trait and their subsequent use in marker aided selection, and (ii) to develop a molecular framework map of jute.

\section{Materials and Methods}

Extraction of DNA: Seeds of jute cultivars, O-72 and O-7/95 and leaf tissues of the $\mathrm{F}_{2}$ population were obtained from the Bangladesh Jute Research Institute (BJRI). For the isolation of total genomic DNA from the leaf tissues of $\mathrm{F}_{2}$ as well as from the seeds of O-72 and O-7/95, CTAB method without phenol was chosen because this method gave good yields of total genomic DNA of high molecular weight (Delaporta et al. 1983). The genomic DNAs along with $\lambda$ DNA were run on a $0.8 \%$ agarose gel which was stained by ethidium bromide solution and visualized using UV illumination and documented by Kodak Biodoc system. The DNAs were quantified by comparing with fluorescence of known concentration of $\lambda$ DNA. The final DNA concentration of each template stock was adjusted to $50 \mathrm{ng} / 1$.

Microsatellite primers: Linkage analysis of $35 \mathrm{~F}_{2}$ jute DNA samples was carried out by ten microsatellite primers (Table 1). The microsatellite enriched library was constructed commercially from Vizon Sci. Inc., BC Research Complex 3650, Westbrook Mall, Vancouver, British Columbia, Canada. Clones containing simple sequence repeats were sequenced and from these sequences the microsatellite sites were identified and SSR primers were designed. Primers were designed manually using the following standard rule: (i) 20-25 nucleotides in length, (ii) 40-60\% GC content, and non-complementary $3^{\prime}$ nucleotides, (iii) the expected sizes of the amplification products to be between 115 and $300 \mathrm{bps}$ and (iv) annealing temperatures to be between approximately $58-61^{\circ} \mathrm{C}$ with no greater than $3^{\circ} \mathrm{C}$ difference in $\mathrm{T}_{\mathrm{m}}$ between primers of each pair.

PCR amplification: PCR amplification was conducted with 251 reaction mixtures containing $50 \mathrm{ng}$ of jute genomic DNA, $10 \mathrm{M}$ of each primer pair, 10X PCR buffer, $50 \mathrm{mM} \mathrm{MgCl} 2,2 \mathrm{mM}$ 
dNTPs, 0.2 unit Taq DNA polymerase using a GeneAmp® PCR system 9700 (Applied Biosystems). The amplification was programmed as follows: Preheating for $5 \mathrm{~min}$ at $95^{\circ} \mathrm{C} ; 35$ cycles, each for $30 \mathrm{~s}$ at $95^{\circ} \mathrm{C}$ (denaturation), $40 \mathrm{~s}$ at the annealing temperature of a particular primer pair, and $30 \mathrm{~s}$ at $72^{\circ} \mathrm{C}$ (extension) and a final extension at $72^{\circ} \mathrm{C}$ for $5 \mathrm{~min}$, followed by cooling at $4^{\circ} \mathrm{C}$ for infinite period. For different primers different annealing temperatures were employed. For SSR primers the optimum annealing temperature used was between 55 and $62^{\circ} \mathrm{C}$.

Table 1. List of SSR primers used, showing their $\mathbf{T}_{m}$, GC content, product sizes and the standardized annealing temperatures.

\begin{tabular}{|c|c|c|c|c|c|c|c|c|}
\hline \multirow{2}{*}{$\begin{array}{c}\text { Primer } \\
\text { No. }\end{array}$} & \multicolumn{2}{|c|}{ Primer pair } & \multicolumn{2}{|c|}{$\mathrm{T}_{\mathrm{m}}\left({ }^{\circ} \mathrm{C}\right)$} & \multicolumn{2}{|c|}{ GC $\%$} & \multirow{2}{*}{$\begin{array}{l}\text { Product } \\
\text { size ( bp) }\end{array}$} & \multirow{2}{*}{$\begin{array}{c}\text { Annealing } \\
\text { temp. }\end{array}$} \\
\hline & $\mathrm{F}$ & $\mathrm{R}$ & $\mathrm{F}$ & $\mathrm{R}$ & $\mathrm{F}$ & $\mathrm{R}$ & & \\
\hline 51 & HK-F-SSR101 & HK-R-SSR102 & 58.9 & 57.7 & 33.3 & 40.9 & 200 & 58 \\
\hline 54 & HK-F-SSR107 & HK-R-SSR108 & 58.4 & 62.4 & 55.0 & 39.1 & 211 & 59 \\
\hline 56 & HK-F-SSR 111 & HK-R-SSR112 & 60.4 & 58.4 & 45.0 & 50.0 & 115 & 58 \\
\hline 59 & HK-F-SSR 117 & HK-R-SSR 118 & 61.2 & 61.0 & 43.5 & 52.2 & 306 & 60 \\
\hline 63 & HK-F-SSR125 & HK-R-SSR126 & 60.8 & 60.8 & 45.5 & 40.9 & 133 & 60 \\
\hline 64 & HK-F-SSR127 & HK-R-SSR 128 & 58.9 & 59.4 & 40.9 & 37.5 & 192 & 59 \\
\hline 66 & HK-F-SSR131 & HK-R-SSR132 & 62.7 & 60.8 & 45.5 & 30.8 & 136 & 61 \\
\hline 69 & HK-F-SSR137 & HK-R-SSR138 & 62.7 & 60.4 & 50.0 & 43.5 & 146 & 61 \\
\hline 74 & HK-F-SSR147 & HK-R-SSR148 & 58.9 & 59.2 & 39.1 & 36.4 & N/A & 59 \\
\hline 79 & HK-F-SSR157 & HK-R-SSR 158 & 59.4 & 58.7 & 42.9 & 36.4 & 210 & 58 \\
\hline
\end{tabular}

Separation and staining of PCR products: The amplified PCR products were subjected to electrophoresis in two gel systems, agarose gel (2\%) and polyacrylamide gel (40\% acrylamide/ bis-acrylamide, $10 \%$ ammonium per sulfate, $5 \mathrm{X}$ TBE buffer, Gel loading dye). The agarose gel electrophoresis was performed for confirmation of the PCR amplification. For obtaining better resolution of polymorphic bands, amplified PCR products were subjected to PAGE which was carried out in $1 \mathrm{X}$ TBE buffer at $100 \mathrm{~W}$ for about 2 hours. After electrophoresis, the products were stained in ethidium bromide and distained in $\mathrm{ddH}_{2} \mathrm{O}$ and then visualized and photographed under UV light using Kodak electrophoresis documentation and analysis system.

Scoring and analysis of the data: The amplified products were scored for further analysis. During scoring, only intense and clearly resolved amplification products that were reproducible in multiple runs were considered for linkage analysis. Polymorphisms were scored for length variation of bands on polyacrylamide gels. The size of the SSR markers varied from 100 $300 \mathrm{bp}$.

The PCR amplification products of $\mathrm{F}_{2}$ plant DNA were scored as $\mathrm{A}, \mathrm{B}, \mathrm{H}$ and null (-) by comparing with PCR amplification products of parental DNA (O-72 and O-7/95). When the bands resembled the parental (O-7/95: mite tolerant plant) DNA, they were designated as "A" (homozygous). Similarly, the bands resembling the parental (O-72: mite sensitive plant) DNA were designated as "B" (homozygous). The bands, when resembled both the parental (O-7/95 and O-72) DNA, were designated as "H" (heterozygous). When no bands were obtained after PCR amplification with specific SSR primer from plant DNA, they were scored null (-). A phenotypic marker was scored as ' $\mathrm{A}$ ' for mite tolerant plant and ' $\mathrm{B}$ ' for mite sensitive plant. It is known that different pathogen races or insect biotypes based on host pathogen or host parasite interaction can 
be used as a marker since the genetic constitution of an organism can affect its susceptibility to pathogens or parasites (Ribaut et al. 2001).

Linkage map construction: The linkage map of jute genome was constructed using software MAPMAKER version 3.0 (stat soft 1994) considering 10 SSR markers and one phenotypic marker with 35 individuals of an $\mathrm{F}_{2}$ population. A logarithm of the odds ratio (LOD) score of 3.0 and a maximum distance of $50 \mathrm{cM}$ was considered for linkage analysis. A raw data was prepared for construction of a linkage map. This raw format contained the polymorphic bands which were scored as $\mathrm{A}, \mathrm{B}, \mathrm{H}$ and null (-).

\section{Results and Discussion}

Genotype determination between mite sensitive and tolerant jute varieties in segregating $F_{2}$ population by comparing the two parents.

In the present investigation, $43 \mathrm{SSR}$ markers were used for assessing variation between the two parents used in developing the mapping $F_{2}$ population. Of these 43 markers, 10 were found capable of distinguishing between the parents. These primers were subsequently used for genotype determination of the segregating $\mathrm{F}_{2}$ population because they produced polymorphic bands between mite sensitive parent $(\mathrm{O}-72)$ and mite tolerant parent $(\mathrm{O}-7 / 95)$.

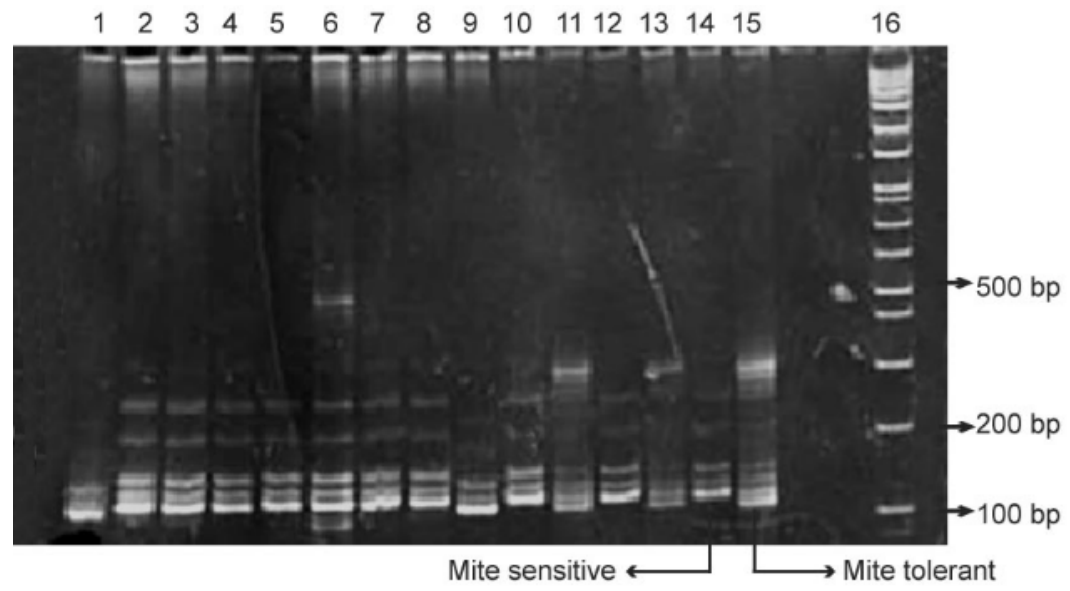

Fig. 1. A representative gel photograph used in scoring of $\mathrm{F}_{2}$ population using SSR primer $\mathrm{M} 63$.

$F_{2}$ population: Lanes 1-13; Parent O-72 (mite sensitive): Lane 14; Parent O-7/95 (mite tolerant): Lane $15 ; 1 \mathrm{~Kb}+$ Ladder: Lane 16.

Scoring and analysis of the data: Ten pairs of SSR primers were used to amplify $35 \mathrm{~F}_{2}$ plant DNA. The SSR markers were scored for determining parental or recombinant phenotype of the $F_{2}$ population. Based on the similarity of desired band size of the PCR product by M-56 with resistant parent, 12 plants were scored as 'A' (Table 2). Five plants were scored as ' $\mathrm{H}$ ' for the presence of bands similar to both resistant and sensitive parent. Twelve plants were scored as ' $\mathrm{B}$ ' for the presence of band only similar to sensitive parent. The remaining six plants were scored as null (-) because of the ambiguity resulting from dissimilarity of band size with parents. Scoring ambiguous data affect mapping result more negatively rather than scoring simply as null. 
Table 2. Scoring SSR markers for determining parental or recombinant phenotype of the $\mathrm{F}_{2}$ population.

\begin{tabular}{|c|c|c|c|c|c|c|c|c|c|c|c|}
\hline $\begin{array}{l}\text { Plant } \\
\text { No. }\end{array}$ & $\begin{array}{c}\text { SSR } \\
\text { M-51 }\end{array}$ & $\begin{array}{c}\text { SSR } \\
\text { M-54 }\end{array}$ & $\begin{array}{c}\text { SSR } \\
\text { M-56 }\end{array}$ & $\begin{array}{c}\text { SSR } \\
\text { M-59 }\end{array}$ & $\begin{array}{c}\text { SSR } \\
\text { M-63 }\end{array}$ & $\begin{array}{c}\text { SSR } \\
\text { M-66 }\end{array}$ & $\begin{array}{c}\text { SSR } \\
\text { M-69 }\end{array}$ & $\begin{array}{c}\text { SSR } \\
\text { M-64 }\end{array}$ & $\begin{array}{c}\text { SSR } \\
\text { M-79 }\end{array}$ & $\begin{array}{c}\text { SSR } \\
\text { M-74 }\end{array}$ & $\begin{array}{c}\text { Phenotypic } \\
\text { marker }\end{array}$ \\
\hline 1 & A & A & A & B & A & A & - & B & A & A & B \\
\hline 2 & A & B & B & B & B & B & B & B & B & A & B \\
\hline$* 3$ & A & B & B & A & B & A & - & B & B & $\mathbf{A}$ & A \\
\hline 4 & A & B & B & B & B & B & - & A & B & A & B \\
\hline 5 & A & B & A & A & B & B & A & B & B & A & B \\
\hline 6 & B & B & A & B & B & B & A & B & B & B & B \\
\hline 7 & B & B & A & A & B & B & A & A & B & B & B \\
\hline 8 & A & B & B & B & B & B & A & B & B & B & B \\
\hline$* 9$ & A & B & $\mathbf{A}$ & $\mathbf{A}$ & $\mathbf{A}$ & $\mathbf{A}$ & $\mathbf{A}$ & B & $\mathbf{A}$ & A & $\mathbf{A}$ \\
\hline 10 & A & B & B & - & B & B & B & B & B & A & B \\
\hline$* 11$ & $\mathbf{A}$ & - & H & - & $\mathbf{A}$ & $\mathbf{A}$ & B & B & $\mathbf{A}$ & $\mathbf{A}$ & $\mathbf{A}$ \\
\hline 12 & B & B & B & - & B & A & - & - & B & B & B \\
\hline 13 & A & B & B & - & $\mathrm{H}$ & B & B & - & A & B & B \\
\hline 14 & A & A & A & A & A & A & A & A & B & B & B \\
\hline$* 15$ & B & $\mathbf{A}$ & H & A & A & B & B & A & $\mathbf{A}$ & A & A \\
\hline$* 16$ & - & B & H & A & B & A & A & A & $\mathbf{A}$ & B & A \\
\hline 17 & A & A & $\mathrm{H}$ & B & B & A & A & A & A & B & B \\
\hline 18 & - & - & - & - & - & A & B & A & B & B & B \\
\hline 19 & - & A & B & B & A & B & B & B & A & A & B \\
\hline 20 & - & A & A & A & A & A & A & B & B & A & B \\
\hline$* 21$ & A & B & A & B & B & A & - & A & $\mathbf{A}$ & B & A \\
\hline 22 & B & B & A & A & B & B & B & A & B & B & B \\
\hline 23 & - & A & - & - & - & A & B & A & - & B & B \\
\hline 24 & A & - & $\mathrm{H}$ & A & B & B & A & A & $\mathrm{H}$ & B & B \\
\hline$* 25$ & B & $\mathbf{A}$ & $\mathbf{A}$ & A & A & A & B & A & A & B & A \\
\hline 26 & A & - & - & - & - & B & - & B & A & - & B \\
\hline 27 & B & - & - & - & - & B & B & A & A & - & B \\
\hline 28 & B & - & B & - & A & B & - & - & - & - & B \\
\hline 29 & A & A & A & - & A & B & B & B & B & - & B \\
\hline 30 & A & A & B & - & - & B & A & A & A & - & B \\
\hline 31 & A & A & B & - & B & B & A & A & - & - & B \\
\hline 32 & B & A & B & - & B & B & - & A & B & A & B \\
\hline 33 & B & - & - & $\mathrm{H}$ & A & B & B & B & B & A & B \\
\hline 34 & A & - & - & - & B & B & B & - & B & - & B \\
\hline 35 & B & - & A & $\mathrm{H}$ & B & - & A & - & - & - & B \\
\hline
\end{tabular}

$*$ and the numbers and alphabets in bold face indicate the seven mite tolerant $\mathrm{F}_{2}$ plants as per field data. 
The segregation of individual markers was analyzed by chi-square test at $1 \%$ level of significance and the following result (Table 3) was obtained.

Table 3. Results of segregation test (Generation: $F_{2}$; No. of progenies: 35; No. of markers: 11).

\begin{tabular}{lcccc}
\hline Marker & N & Ratio & Chi-square value & P-value \\
\hline M-51 & 30 & $19: 0: 11$ & 30.09 & $0.0000 * * *$ \\
M-54 & 26 & $12: 0: 14$ & 21.86 & $0.0000 * * *$ \\
M-56 & 29 & $12: 5: 12$ & 11.34 & $0.0034 * *$ \\
M-59 & 19 & $11: 0: 8$ & 18.14 & $0.0001 * * *$ \\
M-63 & 30 & $11: 1: 18$ & 25.91 & $0.0000 * * *$ \\
M-66 & 34 & $14: 0: 20$ & 35.11 & $0.0000 * * *$ \\
M-69 & 27 & $13: 0: 14$ & 22.71 & $0.0000 * * *$ \\
M-64 & 30 & $15: 0: 15$ & 26.43 & $0.0000 * * *$ \\
M-79 & 31 & $13: 1: 17$ & 25.40 & $0.0000 * * *$ \\
M-74 & 26 & $14: 0: 12$ & 21.86 & $0.0000 * * *$ \\
M-11 & 35 & $7: 0: 28$ & 60.20 & $0.0000 * * *$ \\
\hline
\end{tabular}

** and $* * *$ infer significance level, which differed at $\mathrm{p}<0.005$ and $\mathrm{p}<0.001$, respectively.

Low P-values indicate that markers have effectively segregated from $F_{1}$ in to $F_{2}$ population and it can be inferred at $1 \%$ significance level that two different bands for each marker is due to the presence of two different alleles and not for two different polymorphic state of a marker present in same DNA molecule in $\mathrm{F}_{1}$ population.

Construction of linkage map: Segregation of 11 markers (10 SSR and 1 phenotypic marker) among $35 \mathrm{~F}_{2}$ population was analyzed to construct a genetic linkage map. The distribution of the molecular markers on the different linkage groups was analyzed. Two linkage groups were observed at minimum of LOD score 3.00 and maximum of $50.0 \mathrm{cM}$ distance. Group1 was constituted of markers M-54 and M-63 and distance between these two markers were $23.5 \mathrm{cM}$. Group2 constituted of markers M-66 and M-11 (phenotypic marker) and distance between these two markers was found to be $37.7 \mathrm{cM}$.

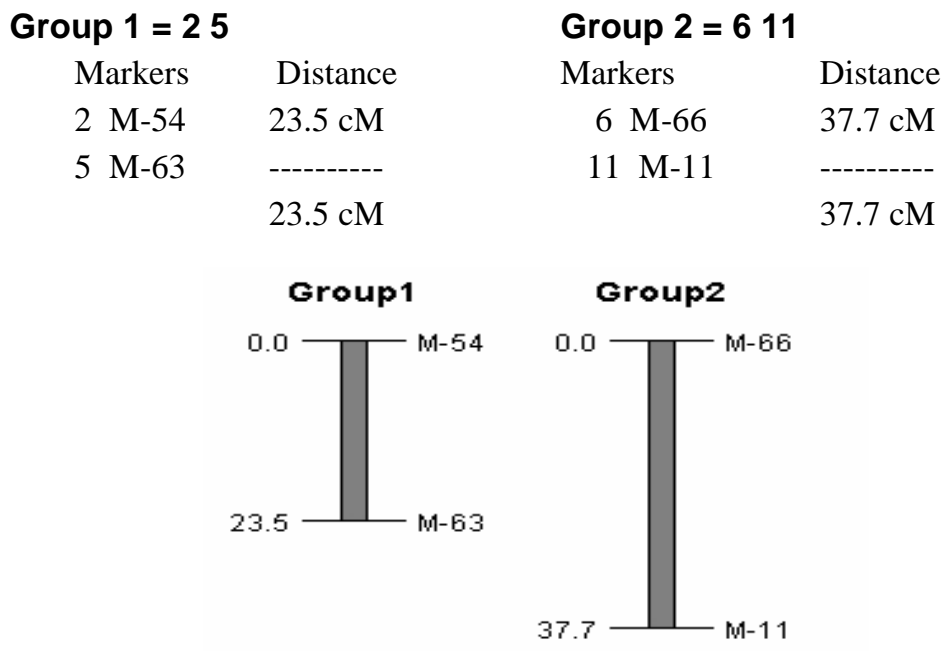

Fig. 2. Linkage map showing $\mathrm{cM}$ distance between markers. 
The distances between the remaining markers were such that they could not be assigned to any linkage groups. When these remaining 7 markers were given as input to the mapmaker programme, the following order was observed among markers with the minimum total distance obtained as $479.5 \mathrm{cM}$ with log-likelihood as -110.67 :

$\begin{array}{cc}\text { Unlinked }=13478910 \\ \text { Markers } & \text { Distance } \\ 10 \mathrm{M}-74 & 93.6 \mathrm{cM} \\ 1 \mathrm{M}-51 & 76.4 \mathrm{cM} \\ 7 \mathrm{M}-69 & 69.4 \mathrm{cM} \\ 3 \mathrm{M}-56 & 52.5 \mathrm{cM} \\ 4 \mathrm{M}-59 & 118.4 \mathrm{cM} \\ 8 \mathrm{M}-64 & 69.3 \mathrm{cM} \\ 9 \mathrm{M}-79 & ------- \\ & 479.5 \mathrm{cM} \quad 7 \text { markers } \quad \text { log-likelihood }=-110.67\end{array}$

The unique chromosome number of cultivar Corchorus species is seven $(2 \mathrm{n}=14)$; therefore, seven linkage groups were expected to represent the whole genome, since the number of linkage groups are the same as the unique chromosome number (Zickler et al. 1984). But, for linkage mapping, this effort was very limited and the total number of loci (ten) was also very low. By increasing the number of markers ( 150 to 300) and by increasing the population size (more than 100), a marker dense saturated linkage map of jute genome can be obtained. The saturated map will help in future to identify the locations of genes responsible for mite resistance trait in jute by positional cloning. Most linkage maps have been constructed with far more markers than the number used in this study. A total of 769 markers were used to analyze the polymorphism between a soybean mosaic virus (SMV) resistant and sensitive soybean parents for linkage analysis and mapping of the SMV resistance gene (Fu et al. 2006). Among them 277 were polymorphic. As expected from the large number of markers used the average distance between markers was 11.8 $\mathrm{cM}$, which is a very dense map. Twenty linkage groups were obtained and the numbers of markers in each group varied from 2 to 19.

It may be noted that in our study only markers which were polymorphic were used. Thus the 10 markers used were all polymorphic.

Genotypic variation in $F_{2}$ mite resistant plants: Molecular marker scores together with phenotypic data have been used to increase yield and resistance to crop pests (Johnson 2004, Shalini et al. 2007). Some important traits in cotton such as those linked to agronomic and fiber quality have been mapped using SSR markers which have facilitated the development of markers associated with Verticillium wilt resistance (Wang et al. 2008).

The high resistance of O-7/95 to mites makes it an ideal candidate for providing new genetic variation useful for improving disease resistance in sensitive varieties. A total of ten SSR markers were evaluated after PCR amplification of $35 \mathrm{~F}_{2}$ plant DNA. Out of $35 \mathrm{~F}_{2}$ plants, only seven plants were mite resistant (From field data; Source: BJRI). Analysis of the data (Table 2) showed genotypic variation in $\mathrm{F}_{2}$. From Table 4, it was observed that none of the mite tolerant plants possessed $100 \%$ 'A' (tolerance) genotype.

From the data (Table 2) and from the linkage map (Fig. 2) it was observed that marker-66 showed linkage with a mite resistant trait. Out of seven resistant plants (Table 5), genotype of the six plants matched with the phenotype. But in one tolerant plant, sensitive-like genotype was observed. So, $85.71 \%$ of mite resistance genotypes among phenotypically resistant plants show linkage of mite resistant trait to M-66 marker. The remaining $14.29 \%$ of the characteristics, which cannot be explained can be inferred as rare crossing over or another copy of this same resistance 
gene may be present in this plant which is not linked with marker 66 and this may impart resistance in this plant. It is known that disease resistance gene products do not act alone in controlling defense reactions (Hubert et al. 2001). It is reported that rare germinal unequal crossing-over can lead to recombinant gene formation and gene duplication (Jelesko et al. 1999).

Table 4. Genetic variation in mite resistant jute plants.

\begin{tabular}{cccccc}
\hline \multirow{2}{*}{$\begin{array}{c}\text { SSR } \\
\text { marker }\end{array}$} & \multicolumn{2}{c}{$\begin{array}{c}\text { Number of segregating } \mathrm{F}_{2} \text { plants (Phenotype }=\text { Mite tolerant } \\
\text { plant); Total mite tolerant plants }=7\end{array}$} & $\begin{array}{c}\text { \% of A genotype in } \\
\text { tolerant plants }\end{array}$ \\
\cline { 2 - 5 } & Genotype-A & Genotype-B & Genotype-H & Null (-) & \\
\hline M-51 & 4 & 2 & 0 & 1 & 66.67 \\
M-54 & 2 & 4 & 0 & 1 & 33.33 \\
M-56 & 3 & 1 & 3 & 0 & 42.86 \\
M-59 & 5 & 1 & 0 & 1 & 83.33 \\
M-63 & 4 & 3 & 0 & 0 & 57.14 \\
M-64 & 3 & 4 & 0 & 0 & 42.86 \\
M-66 & $\mathbf{6}$ & $\mathbf{1}$ & $\mathbf{0}$ & $\mathbf{0}$ & $\mathbf{8 5 . 7 1}$ \\
M-69 & 2 & 3 & 0 & 2 & 40.00 \\
M-79 & 6 & 1 & 0 & 0 & 85.71 \\
M-74 & 4 & 3 & 0 & 0 & 57.14 \\
\hline
\end{tabular}

A = Mite tolerant trait; B = Mite sensitive trait; H - Heterozygous; Null (-) means no bands were obtained after PCR amplification.

Out of 27 mite sensitive $F_{2}$ plants (Table 5), eight plants showed genotype A (tolerance) for marker M-66. In these eight plants, a resistant trait linked to marker-66 was inherited together and in these plants, the intensity of mite infestation was very low. So, there is possibility that mite resistance is a polygenic trait and the presence of only one gene conferring resistance cannot prevent these plants completely from mite attack. Using SSR markers on coconut Shalini et al. (2007) have shown that the markers associated with mite resistance were located on different chromosomes indicating the presence of multiple QTLs for mite resistance. M-66 associated with the trait could be used in marker assisted selection for mite resistance in jute breeding or could be used in gene pyramiding.

Table 5. Use of marker M-66 in genotyping mite tolerant and mite sensitive jute plants.

\begin{tabular}{ccccccc}
\hline \multirow{2}{*}{ Primer } & & \multicolumn{2}{c}{ For sensitive plant } & & \multicolumn{2}{c}{ For resistant } \\
\cline { 3 - 3 } \cline { 5 - 6 } M-66 & No. of plants & Genotype & & No. of plants & Genotype \\
\cline { 2 - 3 } & 8 & A & & 6 & A \\
& 19 & B & & 1 & B \\
& Total $=27$ & & & Total $=7$ & \\
\hline
\end{tabular}

However, in this study no QTLs for resistance segregating in the progeny were identified. Quantitative trait loci analysis requires the development of genetic maps with a large number of markers to provide full coverage of the genome. Therefore, the failure to obtain any QTL could possibly be for one or more of the following reasons: the markers did not cover the whole of the genome; there were unfavorable repulsion linkages between the QTLs and markers, or the gene effects were not large enough to be detected in an experiment of the size conducted. Bradshaw et al. (1998) has reported similar findings in their work on the identification of AFLP and SSR 
markers associated with quantitative resistance to Globodera pallida (Stone) in tetraploid potato (Solanum tuberosum subsp. tuberosum) with a view to marker-assisting selection.

Results of present work indicate that there are good prospects for detecting QTLs and using marker-assisted selection in a jute breeding programme, provided in future the population size is increased to over 250 and more SSR markers are used. In this study PCR-based markers have been successfully used in establishing linkage between some SSR markers and demonstrating linkage of one of these SSR markers to resistance to jute yellow mite, a major jute pest.

However, further efforts are required to identify more closely linked markers for the purpose of application to MAS. Molecular marker maps, the necessary framework for any MAS programme, have been constructed for many agriculturally important species by using molecular markers (Moose and Mumm 2008). By using molecular markers the knowledge gained about genetic relationships among germplasm sources may guide choice of parents for production of hybrids or improved populations (Collard and Mackill 2008). This technology can significantly improve the efficiency of jute varietal development programs and reduce time and costs substantially thus effectively doubling the capacity of research programs, such as marker assisted breeding for resistance to jute yellow mite.

\section{Acknowledgment}

The authors are grateful to Dr. Samiul Hoque, Principal Scientist of the Bangladesh Jute Research Institute for providing the seeds and leaf tissues of the $F_{2}$ population and to Shahidul Islam for useful suggestions. The authors are also grateful to the US Department of Agriculture for financial support.

\section{References}

Akkaya, M.S., A.A. Bhagwat and P.B. Cregan. 1995. Length polymorphisms of simple sequence repeat DNA in soybean. Genetics 132: 1131-1139.

Akter, J., M.S. Islam, A.A. Sajib, N. Ashraf, S. Haque and H. Khan. 2008. Microsatellite markers for determining genetic identities and genetic diversity among jute cultivars. Australian J. Crop Sci. 1(3): 97-107.

Bangladesh Jute Research Institute. 1990. Effect of intensity of yellow mite infestation on yield of O-4 jute under field conditions. Annual report 1990. Bangladesh Jute Res. Inst., Dhaka, Bangladesh.

Bradshaw, J.E., C.A. Hackett, R.C. Meyer, D. Milbourne, J.W. McNicol, M.S. Phillips and R.Waugh. 1998. Identification of AFLP and SSR markers associated with quantitative resistance to Globodera pallida (Stone) in tetraploid potato ( Solanum tuberosum subsp. tuberosum) with a view to marker-assisted selection. Theor. Appl. Genet. 97: 202-210.

Bryan, G.J., A.J. Collins, P. Stephenson, A. Orry, J.B. Smith and M.D. Gale. 1997. Isolation and characterization of microsatellites from hexaploid bread wheat. Theor. Appl. Genet. 94: 557-563.

Burr, B., F.A. Burr, K.H. Thompson, M.C. Albertson and C.W. Stuber. 1988. Gene mapping with recombinant inbreds in maize. Genetics 118: 519-526.

Chin, E.C.L., M.L. Senior, H. Shu and J.S.C. Smith. 1996. Maize simple repetitive DNA sequences: Abundance and allele variation. Genome 39: 866-873.

Clark M.S. and W.J. Wall. 1996. Chromosomes: The Complex Code. Chapman and Hall, New York.

Collard B.C.Y. and D.J. Mackill. 2008. Marker assisted selection: An approach for precision plant breeding in the twenty-first century. Philos. Trans. R. Soc. London Ser. B. Biol. Sci. 363: 557-572.

Cregan, P.B., T. Jarvik, A.L. Bush, R.C. Shoemaker, K.G. Lark, A.L. Kahler, N. Kaya, T.T. Van-Toai, D.G. Lohnes, J. Chung and J.E. Specht. 1999. An integrated genetic linkage map of the soybean genome. Crop Sci. 39: 1464-1490. 
Davis, G.L., M.D. McMullen, C. Baysdorfer, T. Musket, D. Grant, M. Staebell, G. Xu, M. Polacco, L. Koster, K. Houchins, S. Chao and E.H. Coe, Jr. 1999. A maize map standard with sequenced core markers, grass genome reference points, and 932 ESTs in a 1736-locus map. Genetics 152: 1137-1172.

Delaporta, S.L., J. Wood, and J.B. Hicks. 1983. A plant DNA minipreparation. Version II. Plant Mol. Biol. Rep. 4: 19-21.

Dib, C., S. Faure, C. Fizames, D. Samson, N. Drouot, A. Vignal, P. Millaseau, S. Marc, J. Hazan, E. Seboun, M. Lathrop, G. Gabor, J. Moissette and J. Weissenbach. 1996. A comprehensive genetic linkage map of the human genome based on 5264 microsatellites. Nature 380: 152-154.

Dietrich, W.F., J. Miller, R. Steen, M.A. Merchant, D. Damronboles, Z. Husai, R. Dredge, M.J. Daly, K.A. Ingalls, T.J. O’Connor, C.A. Evans, M.M. DeAngelis, D.M. Levinson, L. Kruglyak, N. Goodman, N.G. Copelang, N.A. Jenkins, T.L. Hawkins, L. Stein, D.C. Page and E.S. Lander. 1996. A comprehensive genetic map of the mouse genome. Nature 380: 149-152.

Fu, S., Y. Zhan, H. Zhi, J. Gai and D. Yu. September. 2006. Mapping of SMV resistance gene Rsc-7 by SSR markers in soybean. Genetica 128(1-3): 63-69.

Gardiner, J.M., E.H. Coe, S. Melia-Hancock, D.A. Hoisington and S. Chao. 1993. Development of a Core RFLP Map in maize using an immortalized $F_{2}$ population. Genetics 134(3): 917-930.

Hulbert, S.H., C.A. Webb, S.M. Smith and Q. Sun. 2001. Resistance gene complexes: Evolution and utilization. Annu. Rev. Phytopathol. 39: 285-312.

Jelesko, J.G., R. Harpe, M. Furuya and W. Gruissem. 1999. Rare germinal unequal crossing-over leading to recombinant gene formation and gene duplication in Arabidopsis thaliana. Proc. Natl. Acad. Sci. USA 96: $10302-10307$.

Johnson G.R. 2004. Marker assisted selection. In: Plant Breeding Reviews, Long Term Selection: Maize, J Janick, Ed., 24: 293-309. John Wiley, Hoboken, NJ.

McCouch, S.R., X. Chen, O. Panaud, S. Temnykh, Y. Xu, Y.G. Cho, N. Huang, T. Ishii and M. Blair. 1997. Micro-satellite marker development, mapping and applications in rice genetics and breeding. Plant Mol. Biol. 35: 88-89.

Milbourne, D., R.C. Meyer, A.J. Collins, L.D. Ramsay, C. Gebhardt and R. Waugh. 1998. Isolation, characterization and mapping of simple sequence repeat loci in potato. Mol. Gen. Genet. 259: 233-243.

Mir, R.R., S. Rustgi, S. Sharma, R Singh, A. Goyal, J. Kumar, A. Gaur, A.K. Tyagi, H. Khan, M.K. Sinha, H.S. Balyan and P.K. Gupta. 2008. A preliminary genetic analysis of fibre traits and the use of new genomic SSRs for genetic diversity in jute. Euphytica. 161: 413-427.

Moose, S.P. and R.H. Mumm. 2008. Molecular Plant Breeding as the Foundation for 21st Century Crop Improvement. Plant Physiology 147: 969-977.

Peters J.L., F. Cnudde and T. Gerats. 2003. Forward genetics and map-based cloning approaches. Trends in Plant Sci. 8: 484-491.

Ribaut, J.-M. 2001. Genetic basis of physiological traits. In: Application of Physiology in Wheat Breeding, CIMMYT, Mexico.

Röder, M.S., V. Korzun, K. Wendehake, J. Plaschke, M.H. Tixier, P. Leroy and M.W. Ganal 1998. A microsatellite map of wheat. Genetics 149: 2007-2023.

Staub, J.E., F.C. Serquen and M. Gupta. 1996. Genetic markers, map construction, and their application in plant breeding. HortScience 31: 729-741.

Shalini, K.V., S. Manjunatha, P. Lebrun, A. Berger, L. Baudouin, N. Pirany, R..M. Ranganath and D T. Prasad. 2007. Identification of molecular markers associated with mite resistance in coconut (Cocos nucifera L.). Genome 50(1):35-42.

Taramino, G. and S. Tingey. 1996. Simple sequence repeats for germplasm analysis and mapping in maize. Genome 39: 277-287.

Tautz, D., M. Trick and G.A. Dover. 1986. Cryptic simplicity in DNA is a major source of genetic variation. Nature 322: 652-656.

Temnykh, S., W.D. Park, N. Ayres, S. Cartinhour, N. Hauck, L. Lipovich, Y.G. Cho, T. Ishii, and S.R. McCouch. 2000. Mapping and genome organization of microsatellite sequences in rice (Oryza sativa L.). Theor. Appl. Genet. 100: 697-712. 
Vos, P., R. Hogers, M. Bleeker, M. Reijans, T. van de Lee, M. Hornes, A. Frijters, J. Pot, J. Peleman and M. Kuiper. 1995. AFLP: A new technique for DNA fingerprinting. Nucleic Acids Res. 23: 4407-4414.

Williams, J.G.K., A.K. Kubelik, K.J. Livac, J.A. Rafalski and S.V. Tingey. 1990. DNA polymorphisms amplified by arbitary primers are useful as genetic markers. Nucl. Acids Res. 18: 6531-6535.

Wang H.M, Z.X. Lin., X.L. Zhang, W. Chen, X.P. Guo, Y.C. Nie and Y.H. Li. 2008. Mapping and Quantitative Trait Loci Analysis of Verticillium Wilt Resistance Genes in Cotton. Journal of Integrative Plant Biology 50(2): 174-182.

Yang H., M. Shankar, B.J. Buirchell, M.W. Sweetingham and P.M.C. Smith. 2002. Development of molecular markers tagging disease resistance to Diaporthe toxica in narrow-leafed lupin (Lupinus angustifolius). Theo. and Appl. Genet. 105: 265-270.

Zickler, D., G. Leblon, V. Haedens, A. Collard and P. Thuriaux. 1984. Linkage group-chromosome correlations in Sordaria macrospora: Chromosome identification by three dimensional reconstruction of their synaptonemal complex. Current Genetics 8(1): 57-67.

(Manuscript received on 7 July, 2008; revised on 1 November, 2008) 